\title{
Does Virulence Assessment of Vibrio anguillarum Using Sea Bass (Dicentrarchus labrax) Larvae Correspond with Genotypic and Phenotypic Characterization?
}

\author{
Ingeborg Frans ${ }^{1,2,4,5}$, Kristof Dierckens ${ }^{5}$, Sam Crauwels ${ }^{1,2}$, Ado Van Assche ${ }^{1,2}$, Jørgen Leisner ${ }^{3}$, \\ Marianne H. Larsen ${ }^{3}$, Chris W. Michiels ${ }^{4}$, Kris A. Willems ${ }^{1,2}$, Bart Lievens ${ }^{1,2}$, Peter Bossier ${ }^{59}$, \\ Hans Rediers ${ }^{1,2 * 9}$
}

1 Laboratory for Process Microbial Ecology and Bioinspirational Management (PME\&BIM), Thomas More Mechelen, Campus De Nayer, Department of Microbial and Molecular Systems (M2S), KU Leuven Association, Sint-Katelijne-Waver, Belgium, 2 Scientia Terrae Research Institute, Sint-Katelijne-Waver, Belgium, 3 Department of Veterinary Disease Biology, University of Copenhagen, Frederiksberg, Denmark, $\mathbf{4}$ Centre for Food and Microbial Technology, M2S, KU Leuven, Heverlee, Belgium, $\mathbf{5}$ Laboratory of Aquaculture and Artemia Reference Center, Department of Animal Production, Ghent University, Gent, Belgium

\begin{abstract}
Background: Vibriosis is one of the most ubiquitous fish diseases caused by bacteria belonging to the genus Vibrio such as Vibrio (Listonella) anguillarum. Despite a lot of research efforts, the virulence factors and mechanism of $V$. anguillarum are still insufficiently known, in part because of the lack of standardized virulence assays.

Methodology/Principal Findings: We investigated and compared the virulence of $15 \mathrm{~V}$. anguillarum strains obtained from different hosts or non-host niches using a standardized gnotobiotic bioassay with European sea bass (Dicentrarchus labrax L.) larvae as model hosts. In addition, to assess potential relationships between virulence and genotypic and phenotypic characteristics, the strains were characterized by random amplified polymorphic DNA (RAPD) and repetitive extragenic palindromic PCR (rep-PCR) analyses, as well as by phenotypic analyses using Biolog's Phenotype MicroArray ${ }^{\mathrm{TM}}$ technology and some virulence factor assays.

Conclusions/Significance: Virulence testing revealed ten virulent and five avirulent strains. While some relation could be established between serotype, genotype and phenotype, no relation was found between virulence and genotypic or phenotypic characteristics, illustrating the complexity of $V$. anguillarum virulence. Moreover, the standardized gnotobiotic system used in this study has proven its strength as a model to assess and compare the virulence of different $V$. anguillarum strains in vivo. In this way, the bioassay contributes to the study of mechanisms underlying virulence in $V$. anguillarum.
\end{abstract}

Citation: Frans I, Dierckens K, Crauwels S, Van Assche A, Leisner J, et al. (2013) Does Virulence Assessment of Vibrio anguillarum Using Sea Bass (Dicentrarchus labrax) Larvae Correspond with Genotypic and Phenotypic Characterization? PLoS ONE 8(8): e70477. doi:10.1371/journal.pone.0070477

Editor: Dongsheng Zhou, Beijing Institute of Microbiology and Epidemiology, China

Received April 14, 2013; Accepted June 10, 2013; Published August 6, 2013

Copyright: (c) 2013 Frans et al. This is an open-access article distributed under the terms of the Creative Commons Attribution License, which permits unrestricted use, distribution, and reproduction in any medium, provided the original author and source are credited.

Funding: This study was supported by European FP7 project 'Promicrobe - Microbes as positive actors for more sustainable aquaculture' (Project Reference 227197) and by Ghent University project "Host microbial interactions in aquatic production" (BOF12/GOA/022). This work was financially supported by the "Agency for Innovation by Science and Technology in Flanders (IWT)(www.iwt.be)". The funders had no role in study design, data collection and analysis, decision to publish, or preparation of the manuscript.

Competing Interests: The authors have declared that no competing interests exist.

*E-mail: hans.rediers@biw.kuleuven.be

9 These authors contributed equally to this work.

\section{Introduction}

Over the last five decades, the world aquaculture industry has grown considerably and according to the Food and Agriculture Organization (FAO), aquaculture represents the fastest-growing animal-food-producing sector [1]. This development has been accompanied by a transition to more intensive farming methods supporting an increased profitability. A side-effect of these intensified production systems is an increased threat by diseases caused by a variety of microorganisms, including bacteria, fungi, viruses and protozoa. Despite all research activity that has been carried out in order to develop rapid diagnostic tests and effective disease prevention strategies [2], large-scale disease outbreaks are still causing considerable economical losses [1].
Vibriosis, caused by Vibrio (Listonella) anguillarum, has been reported as one of the most important infectious diseases affecting many economically important fish, bivalves and crustaceans [3-5]. Symptoms are red spots on the ventral and lateral areas of the fish and swollen and dark skin lesions that can ulcerate and bleed. Furthermore, the eyes are often infected, initially resulting in opacity, and later on in ulceration and exophthalmia. Internally, the intestines may be distended and filled with a clear, viscous liquid. Outbreaks of this disease often result in high mortality rates of infected fish. Moreover, in acute epizootics, infection spreads so rapidly that the majority of infected fish die without showing any clinical signs [5-7]. Because of this high morbidity and mortality rate, the disease is responsible for severe economic losses in both larviculture and aquaculture worldwide. Disease outbreaks can be 
influenced by water quality and temperature, the amount of stress imposed upon the fish, and the strain and virulence of the bacteria. Out of 23 identified O-serotypes (O1-O23), only serotypes $\mathrm{O} 1$ and $\mathrm{O} 2$, and to a lesser extent serotype $\mathrm{O} 3$, have been linked to vibriosis in fish [8]. The other $V$. anguillarum serotypes represent environmental isolates from sediment, plankton or seawater that are mainly non-pathogenic. Over the last couple of years, knowledge of the virulence of this bacterium has been largely increased by the use of molecular and biochemical analysis approaches $[9,10]$. In general, virulence factors in $V$. anguillarum have been classified into those that are necessary for chemotaxis and motility, for adhesion and invasion, including proteases [11,12], hemolysins [13-16], lipopolysaccharides (LPS) [17-19], and those that are required for bacterial proliferation and persistence. Regarding the latter, it is for example known that siderophore-mediated iron-sequestering systems, enabling growth in iron-limiting conditions, contribute significantly to the virulence of this pathogen. Two different siderophore-mediated systems have been described in $V$. anguillarum strains. In most pathogenic strains of serotype $\mathrm{Ol}$, the system is mediated by the $65 \mathrm{~kb}$ virulence plasmid $\mathrm{pJM} 1$, harbouring genes for the biosynthesis of the siderophore anguibactin and its cognate transport system [20]. In contrast, serotype $\mathrm{O} 2$ strains and some plasmidless serotype $\mathrm{O} 1$ strains produce a chromosomally encoded siderophore vanchrobactin [21-24]. Nevertheless, despite these studies, the exact role and contribution of many of these virulence factors in full $V$. anguillarum virulence remain still largely unknown, e.g. by the lack of epidemiological studies and standardized virulence assays.

Recently, a gnotobiotic sea bass (Dicentrarchus labrax) larvae model system has been developed and optimized for studying hostpathogen interactions and virulence assessment of opportunistic pathogens such as Aeromonas hydrophila and V. anguillarum [25]. The European sea bass was chosen as host because of its high economic importance for larviculture and aquaculture [26]. Briefly, in this system, gnotobiotic larvae are challenged via immersion in inoculated water or encapsulated Artemia sp., followed by an assessment of the survival of the sea bass larvae. In this paper, we investigated and compared the virulence of $15 \mathrm{~V}$. anguillarum strains obtained from different hosts or non-host niches using this standardized gnotobiotic bioassay. Here, the assay has been used for the first time to evaluate the virulence of a comprehensive set of different $V$. anguillarum strains. In addition, to assess potential relationships between virulence and genotypic and phenotypic characteristics, the strains were characterized by two complementary PCR-based genotyping methods, including repetitive extragenic palindromic PCR (rep-PCR) and random amplified polymorphic DNA (RAPD) PCR, and phenotypic analysis using Biolog's Phenotype MicroArray ${ }^{\text {TM }}$ technology [27].

\section{Materials and Methods}

\section{Ethics Statement}

All necessary permits were obtained for the described virulence studies. The experiment was approved by the ethical committee of Ghent University (no. EC2005/95).

\section{Bacterial Strains}

Fifteen $V$. anguillarum strains, representing the major pathogenic serotypes O1, O2 and O3, were used in this study (Table 1). Fourteen strains have been isolated from different species of fish, including sea bass, rainbow trout (Oncorhynchus mykiss) and cod (Gadus morhua L.), while one isolate was recovered from sediment. Furthermore, the isolates were originating from six geographical regions, including Denmark, Norway, Finland, Greece, France and UK. In previous studies, most isolates have been assessed for the presence or absence of the pJM1 virulence plasmid (Table 1) [8,28-33]. Nevertheless, as bacterial strains may lose plasmids over time, presence of the virulence plasmid has been confirmed in this study by isolation and sequencing. In addition, bacterial identities were confirmed as $V$. anguillarum by $16 \mathrm{~S}$ rRNA gene sequencing, followed by BLAST analysis against GenBank (see phylogenetic analysis). Strains were stored in trypticase soy broth (TSB; Oxoid, Erembodegem, Belgium) containing $1 \% \mathrm{NaCl}$ and $15 \%(\mathrm{v} / \mathrm{v})$ glycerol at $-80^{\circ} \mathrm{C}$.

\section{Virulence Testing}

The 15 selected isolates were made rifampicin (Rif) resistant by inoculating the strains at a final density of $10^{7} \mathrm{CFU} \mathrm{mL} \mathrm{m}^{-1}$ in marine broth with addition of an increasing concentration (1$100 \mathrm{mg} \mathrm{L}^{-1}$ ) of Rif. After $24 \mathrm{hrs}$ culturing on a shaker at $28^{\circ} \mathrm{C}$, $1 \%$ of the old culture is used as inoculum for the next culture untill a resistance for $100 \mathrm{mg} \mathrm{L}^{-1}$ Rif by natural mutation is reached. Next, the 15 isolates were subjected to the virulence assay previously developed by Dierckens et al. [25], consisting of a standardized gnotobiotic model system with axenic European sea bass (D. labrax L.) larvae as hosts. To this end, D. labrax eggs were obtained from natural spawning at the hatchery of Ecloserie Marine de Gravelines (France). Following egg disinfection [25], germ-free eggs were allowed to hatch for $60 \mathrm{~h}$. Subsequently, 12 freshly hatched sea bass larvae were aseptically transferred one by one into a transparent sterile screw cap vial with $10 \mathrm{~mL}$ filtered $(0.2 \mu \mathrm{m})$, autoclaved sea water (FASW) containing $10 \mathrm{mg} \mathrm{L}^{-1}$ Rif and sterile fish homogenate equal to three dead sea bass larvae, providing some nutrients to the bacteria in a gnotobiotic environment. Vials were rotated at $4 \mathrm{rpm}$ with an axis tangential to the axis of the vials, providing aeration and avoiding sedimentation awaiting bacterial inoculation. Five days after hatching (DAH 5), sea bass larvae were counted for the first time. In addition, bacterial strains were grown in $10 \%$ marine broth containing $\mathrm{NaCl}$ (resulting in the same salinity as the water in the sea bass larvae experiment, i.e. $36 \mathrm{~g} \mathrm{~L}^{-1}$ ), and incubated on a horizontal shaker at $120 \mathrm{rpm}$ at $16 \pm 0,5^{\circ} \mathrm{C}$ for two days. On DAH 7 , the gnotobiotic sea bass larvae were challenged with a suspension of approximately $10^{5} \mathrm{cfu} \mathrm{mL}^{-1} \mathrm{~V}$. anguillarum (as determined by a spectrophotometer at $550 \mathrm{~nm}$ ). On DAH 9, 11, and 13 (i.e. 2-6 days post-exposure), survival of the sea bass larvae was monitored by microscopic analysis, i.e. by counting the number of living sea bass larvae in relation to the situation at DAH 7. For each strain, 10 replicates were evaluated. Non-challenged larvae, kept under similar conditions, were used as a control. In order to verify the gnotobiotic status of the assay, axenity was tested on DAH 3 by plating fish larvae homogenates and water samples as described by Dierckens et al. [25]. No bacteria could be detected after $72 \mathrm{~h}$ incubation. In addition, after the larvae survival experiment, homogenized fish larvae were plated on $10 \%$ marine agar (MA; Difco Laboratories, Detroit, USA) to check for microbial contamination as well as to verify the identity of the inoculated strains by DNA analysis (RAPD fingerprinting; see further). Throughout the entire experiment, eggs and (challenged) larvae were kept at a salinity of $36 \mathrm{~g} \mathrm{~L}^{-1}$ in a temperaturecontrolled room at $16 \pm 0.5^{\circ} \mathrm{C}$ in constant dim light $(10$ candela steradian $\mathrm{m}^{-2}$ ). Statistical analysis of the larval survival data was performed by means of R v2.12.1. Survival was reported as mean values \pm standard error of the mean (SEM). Data were tested for normality and subjected to non-parametric tests. Kruskal-Wallis one-way analysis was used to compare the survival of the sea bass larvae. Bonferroni test was used for multiple comparisons among 
Table 1. Vibrio anguillarum strains used in this study.

\begin{tabular}{|c|c|c|c|c|c|}
\hline Strain & Host or environment & Origin & Serotype & $\begin{array}{l}\text { Virulence } \\
\text { plasmid }^{\mathbf{a}}\end{array}$ & Reference \\
\hline VIB15 & Sea bass & Greece & 01 & + & 28 \\
\hline VIB93 & Rainbow trout & Denmark & 01 & + & 28 \\
\hline $87-9-116$ & Rainbow trout & Finland & 01 & - & 30 \\
\hline $87-9-117$ & Rainbow trout & Finland & 01 & + & 30 \\
\hline VaNT1 & Rainbow trout & Denmark & 01 & + & 8 \\
\hline S3 4/9 & Mucus, Rainbow trout & Denmark & 01 & - & 29 \\
\hline JLL237 & Rainbow trout & Hjarnø, Denmark & 01 & - & 33 \\
\hline 43 & Sea bass & UK & 01 & - & 31 \\
\hline VIB12 & Sea bass & Greece & $\mathrm{O} 2$ & - & 28 \\
\hline VIB103 & Cod & Denmark & $\mathrm{O} 2$ & $-{ }^{\mathrm{b}}$ & 28 \\
\hline VIB160 & Sediment & Denmark & $\mathrm{O} 2$ & - & 28 \\
\hline JLL143 & Rainbow trout & Denmark & $\mathrm{O} 2$ & - & 33 \\
\hline HI610 & Cod & Norway & $\mathrm{O} 2$ & - & Parisvannet, Norway \\
\hline VIB113 & Rainbow trout & Denmark & $\mathrm{O} 3$ & - & 28 \\
\hline CNEVA NB11008 & Sea bass & France & $\mathrm{O} 3$ & - & 32 \\
\hline
\end{tabular}

$\mathrm{a}_{+}=$Present; $-=$Absent (also confirmed in this study).

${ }^{\mathrm{b}}$ Presence of plasmid $>200 \mathrm{~kb}$

doi:10.1371/journal.pone.0070477.t001

means in case of non-homogeneity. Significance was accepted at $\mathrm{p}<0.05$.

\section{Phylogenetic Analysis}

Genomic DNA was extracted following overnight incubation on marine agar at $28^{\circ} \mathrm{C}$, using the phenol/chloroform extraction method as described by Lievens et al. [34]. Subsequently, the $16 \mathrm{~S}$ ribosomal RNA (rRNA) gene, as well as the genes encoding an Nacetylmuramoyl-L-alanine amidase involved in the separation of daughter cells after cell division (amiB) [35] and an extracellular metalloprotease involved in virulence in $V$. anguillarum (empA) [11] were partially amplified with the primers $63 \mathrm{~F}$ and $1492 \mathrm{R}$, ami8 and ami417, and empAF and empAR, respectively [36-39]. PCR amplification was performed in a total volume of $20 \mu$ l containing $0.3 \mu \mathrm{M}$ of each primer, $0.3 \mathrm{mM}$ of each deoxynucleoside triphosphate (Invitrogen, Merelbeke, Belgium), 2.0 U Taq DNA polymerase (Bioké, Leiden, The Netherlands), 10X ThermoPol Reaction Buffer (Bioké), and $1 \mathrm{ng}$ genomic DNA (as measured by a Nanodrop spectrophotometer). Before amplification, DNA samples were denatured at $94^{\circ} \mathrm{C}$ for $2 \mathrm{~min}$. Subsequently, 35 cycles of the following steps were run: $45 \mathrm{~s}$ at $94^{\circ} \mathrm{C}, 45 \mathrm{~s}$ at $59^{\circ} \mathrm{C}$ (16S rRNA gene, $e m p A)$ or $54^{\circ} \mathrm{C}(a m i B)$, and $45 \mathrm{~s}$ at $72^{\circ} \mathrm{C}$, followed by a final extension step at $72^{\circ} \mathrm{C}$ for $10 \mathrm{~min}$. Sequencing of purified PCR products was performed using the forward primer used for DNA amplification for the $e m p A$ and $a m i B$ amplicons and using the forward and reverse primer for the 16S rRNA gene amplicons. For the latter, forward and reverse sequences were individually trimmed for quality based on the obtained electropherogram, using a Phred-score of $>20$ (i.e. $0.01 \%$ error rate) as a cut-off value. Paired sequences were then aligned using the ClustalW algorithm within the MEGA5 software package [40], followed by manual sequence editing based on the paired electropherograms, leading to an accurate consensus sequence. Subsequently, a phylogenetic analysis was performed based on the in silico concatenated nucleotide sequences comprising 16S rRNA, $a m i B$ and empA. To this end, following multiple sequence alignment performed using ClustalW a Maximum Likelihood tree was constructed using the MEGA5 software. The sequences obtained in this study were deposited in GenBank under the accession numbers KF150774 to KF150818.

\section{DNA Fingerprinting}

DNA extracted from all isolates studied was subjected to two fingerprinting techniques, including RAPD and rep-PCR. With regard to the RAPD analysis, first 20 decamer oligonucleotides, randomly chosen from the Operon primer kits (Operon Technologies Inc, Alameda, CA, USA), were screened on a subset of five bacterial strains from Table 1 to select the most discriminative RAPD primers. Two primers, OPV-12 (5'-ACGCCCCACT-3') and OPN-08 (5'-ACCTCAGCTC-3'), resulted in a clear and discriminating fingerprint, and these were selected for further experiments. Likewise, for the rep-PCR analysis, two primers and one primer set were first tested on the same set of five isolates, including the BOXA1R primer (5'-CTACGGGAAGGGGACGCTGACG- $3^{\prime}$ ), the (GTG) 5 primer $\left(5^{\prime}\right.$ GTGGTGGTGGTGGTG- $3^{\prime}$ ) and the primer pair REP1R-I (5'-IIIICGICGICGICATCIGGC-3') and REP2-I (5'-ICGICTTATCIGGCCTAC-3') [41]. As the BOXA1R and (GTG)5 primers generated only very weak bands or an insufficient number of fragments, only REP1R-I and REP2-I, yielding a clear and discriminating fingerprint, was maintained for analysis of the whole collection. All amplifications were performed using a BioRad T100 thermal cycler in a reaction volume of $20 \mu$ l containing $0.5 \mu \mathrm{M}$ of each primer, $0.15 \mathrm{mM}$ of each deoxynucleoside triphosphate (Invitrogen), 2.0 U Taq DNA polymerase (Bioké), 10X ThermoPol Reaction Buffer (Bioké), and 1 ng genomic DNA (as measured by a Nanodrop spectrophotometer). The reaction mixture was initially denatured at $94^{\circ} \mathrm{C}$ for $2 \mathrm{~min}$, followed by 35 cycles of $1 \mathrm{~min}$ at $94^{\circ} \mathrm{C}, 1 \mathrm{~min}$ at $35^{\circ} \mathrm{C}(\mathrm{RAPD})$ or $40^{\circ} \mathrm{C}$ (repPCR), and 2 (RAPD) or $4 \mathrm{~min}\left(\right.$ rep-PCR) at $72^{\circ} \mathrm{C}$, with a final extension step at $72^{\circ} \mathrm{C}$ for $10 \mathrm{~min}$. Obtained PGR products were separated by loading $7 \mu \mathrm{l}$ of the reaction volume on a $1 \%(\mathrm{w} / \mathrm{v})$ 
agarose gel followed by $120 \mathrm{~min}$ electrophoresis at $4 \mathrm{~V} / \mathrm{cm}$ in $1 \times$ Tris/acetate-EDTA (TAE) buffer. Gels were stained with ethidium bromide and visualized with UV light. A $1 \mathrm{~kb}$ DNA ladder (Smartladder; Eurogentec, Seraing, Belgium) was used as molecular weight marker. Gel images were acquired with the BioChemi System (UVP, Upland, CA, USA). Obtained images were processed by using GelCompar software, version 6.6.4 (Applied Maths, Sint-Martens-Latem, Belgium). Following normalization and background subtraction, fingerprint similarities based on the combined dataset were calculated using the Pearson correlation coefficient. Cluster analysis was performed by the unweighted pair group method with arithmetic averages (UPGMA) [42]. All reactions were performed at least twice to check reproducibility, and yielded similar results. In all analyses, sterile distilled water was used as a negative control.

\section{Phenotyping}

For each strain, carbon source oxidation was determined by Phenotype MicroArray ${ }^{\mathrm{TM}}$ (PM) technology (Biolog, Hayward, CA) using PM plate 1. Using this technology, kinetic profiles are generated by continuously monitoring the metabolic activity during incubation [27]. The inoculum was prepared by growing strains for 24 hours at $25^{\circ} \mathrm{C}$ on trypticase soy agar supplemented with $1 \% \mathrm{NaCl}$. Cells were suspended in $10 \mathrm{ml}$ inoculation fluid (IF-0 supplemented with 1\% (w/v) NaCl, Biolog) until an optical density $(600 \mathrm{~nm})$ of $0.38( \pm 0.02)$ was reached, using a SPECTRAmax PLUS384 UV-vis spectrophotometer (Molecular Devices). The inoculum was diluted (1:5) in inoculation fluid containing dye mix D (Biolog). Each well was inoculated with $100 \mu$ l. Plates were incubated in the OmniLog ${ }^{\circledR}$ automated incubator-reader of Biolog for eight days at $25^{\circ} \mathrm{C}$ and were read every 15 minutes. Resulting data were analyzed using OmniLog ${ }^{\circledR}$ PM Kinetic Analysis software (version 1.6) according to the manufacturer's instructions. Comparison of the isolates was performed by numerical analysis using the Pearson product-moment correlation coefficient and hierarchical clustering with UPGMA. The clustering results were validated using cophenetic correlation [43]. A selection of reactions was performed at least twice to check reproducibility, and yielded similar results.

Additional phenotypic assays associated with virulence have been performed. All enzymatic and hemolytic assays were done according to Natrah et al. [44]. Briefly, overnight cultures of each bacterial strain were diluted to an OD600 of 0.5. For each assay, $5 \mu \mathrm{l}$ of diluted culture was spotted in the middle of the test plate. MA plates supplemented with 1\% Tween 80 (Sigma-Aldrich) or $1 \%$ egg yolk emulsion (Sigma-Aldrich) were used for the lipase and phospholipase assays, respectively. The development of opalescent zones around the colonies was observed and the diameter of the zones was measured after 2-4 days of incubation at $28^{\circ} \mathrm{C}$. The caseinase assay plates were prepared by mixing double strength MA with a $4 \%$ skim milk powder suspension (Oxoid), sterilized separately at $121^{\circ} \mathrm{C}$ for $5 \mathrm{~min}$. Clearing zones surrounding the bacterial colonies were measured after 2 days of incubation. Gelatinase assay plates were prepared by mixing $0.5 \%$ gelatin (Sigma-Aldrich) into MA. After 7 days of incubation, saturated ammonium sulfate $(80 \%)$ in distilled water was poured over the plates and after $2 \mathrm{~min}$, the diameters of the clearing zones around the colonies were measured. Hemolytic assay plates were prepared by supplementing MA with 5\% defibrinated sheep blood (Oxoid). Glearing zones were measured after 2 days of incubation. All assays were done at least in triplicate.

\section{Results}

\section{Virulence Testing}

In order to assess the virulence of $15 \mathrm{~V}$. anguillarum isolates, gnotobiotic sea bass larvae were challenged with $V$. anguillarum, whereupon the larval survival was monitored by microscopical analysis at DAH 9, 11 and 13 (Fig. 1; Table 2). After DAH 13 the sea bass larvae in the control treatment died of starvation, making us to decide to terminate the experiment at DAH 13 (six days after inoculation). Survival on DAH 13 of the sea bass larvae challenged with the serotype O1 strains VaNT1, VIB93, S3 4/9 and 87-9-116 (ranging from $93 \pm 3 \%$ to $78 \pm 8 \%$ survival) was not significantly different from the control group $(89 \pm 4 \%)$. Treatment with the O2 strain VIB12 (67 $\pm 5 \%)$ was significantly different from the axenic control but not significantly different from inoculations with S3 4/ 9 and 87-9-116. As such, based on these observations these five strains were classified as avirulent strains, at least in the gnotobiotic system used here. The other ten strains caused a significantly higher mortality compared to the avirulent strains as well as the axenic control and were classified as virulent strains. Strains VIB15 and 87-9-117, two O1 serotype strains containing the virulence plasmid, showed high virulence towards sea bass larvae $(33 \pm 10 \%$ and $13 \pm 8 \%$ survival, respectively). Remarkably, although strain 87-9-117 was originally isolated from rainbow trout, it also caused high mortality in sea bass larvae, indicating that there is no stringent host-specificity for vibriosis. Two other O1 serotype strains (43 and JLL237), although lacking the virulence plasmid, were also virulent $(22 \pm 5 \%$ and $4 \pm 2 \%$ survival, respectively). Strains VIB103, JLL143, and VIB160, belonging to serotype O2 also caused high mortality $(29 \pm 3 \%, 23 \pm 4 \%$, and $6 \pm 2 \%$ survival, respectively). Apparently, although strain VIB 160 was not isolated from fish but from sediment, it showed high virulence towards sea bass larvae. In addition, all tested $\mathrm{O} 3$ strains (VIB113 and CNEVA NB11008) appeared to be highly virulent $(3 \pm 3 \%$ and $8 \pm 4 \%$ survival, respectively). An independent replication of this gnotobiotic sea bass challenging experiment confirmed the results shown in Fig. 1. For each experiment, the identity of the inoculated strains was confirmed by isolating the bacteria again at the end of the experiment (DAH 13) followed by RAPD fingerprinting, confirming that mortality was caused by the tested $V$. anguillarum strains and not by non-added strains.

\section{DNA Analysis}

To assess a potential relation between virulence and genotypic background, all strains were subjected to both a phylogenetic analysis and DNA fingerprinting. First, a phylogenetic tree was constructed based on the in silico concatenated sequences of the 16S rRNA gene (1365 bp), amiB (365 bp) and empA (371 bp) sequences (Fig. 2). However, due to the high degree of conservation of these genes (98-100\% similarity), not all strains could be discriminated from each other. In particular, five out of the eight O1 strains (87-9-116, 87-9-117, VaNT1, VIB93 and VIB15) showed identical 16S rRNA, amiB and empA sequences, as did the two O3 strains (VIB113, GNEVA NB11008) (Fig. 2).

Next, two RAPD analyses (primers OPV-12 and OPN-08) and one rep-PGR analysis (primer pair REP1R-I and REP2-I) were performed. RAPD and rep-PCR patterns were obtained yielding 5 to 14 distinct bands. The UPGMA dendrogram derived from Pearson correlation based on the combined datasets showed high congruence with the phylogenetic tree (Fig. 3; Table 2). However, the discriminative power displayed was considerably higher with the fingerprinting methods. Only strain VIB12, belonging to serotype O2, clustered differently in both trees. Based on a similarity level of $50 \%, 5$ distinct clusters could be identified in the 


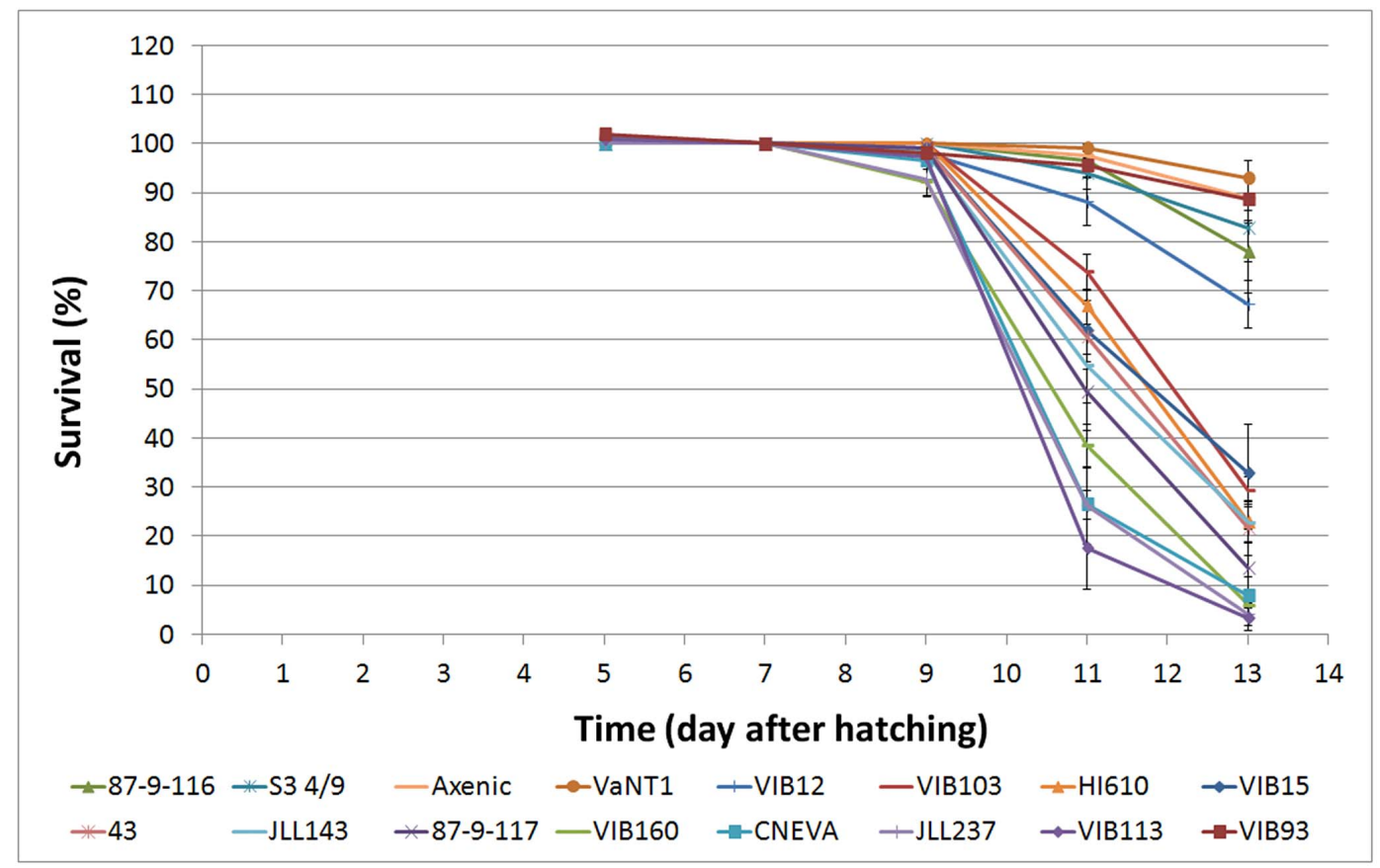

Figure 1. Survival (in percentage) of sea bass larvae during the gnotobiotic experiment (unfed larvae) before and after challenge ( 7 days after hatching) with the 15 selected Vibrio anguillarum isolates. Error bars represent mean \pm SEM $(n=10)$. doi:10.1371/journal.pone.0070477.g001

UPGMA dendrogram. Cluster I only contained Ol serotype strains ( 5 out of the eight studied), while cluster II was comprised of the two O3 strains (fingerprints sharing 100\% similarity), two O2 serotype strains (VIB12 and VIB160) and one O1 strain (S3 4/9)

Table 2. Genotypic and Phenotypic properties of the Vibrio anguillarum strains used in this study.

\begin{tabular}{|c|c|c|c|c|c|c|c|c|c|}
\hline \multirow[t]{2}{*}{ Strain } & \multirow[t]{2}{*}{ Serotype } & \multirow[t]{2}{*}{$\begin{array}{l}\text { Virulence } \\
\text { assay } \\
(\% \\
\text { survival) }^{a}\end{array}$} & \multirow[t]{2}{*}{$\begin{array}{l}\text { Cluster } \\
\text { Genotyping }\end{array}$} & \multirow[t]{2}{*}{$\begin{array}{l}\text { Cluster } \\
\text { Phenotyping }\end{array}$} & \multicolumn{5}{|c|}{ Enzyme assays ${ }^{d}$} \\
\hline & & & & & Lipase & Phospholipase & Caseinase & Hemolytic & Gelatinase \\
\hline VIB15 & 01 & $33 \pm 10$ & 1 & $A$ & - & + & + & + & + \\
\hline VIB93 & 01 & $89 \pm 5$ & 1 & A & + & + & + & + & + \\
\hline $87-9-116$ & 01 & $78 \pm 8$ & 1 & $A$ & + & + & + & - & + \\
\hline 87-9-117 & 01 & $13 \pm 8$ & I & A & + & + & + & + & + \\
\hline VaNT1 & 01 & $93 \pm 3$ & 1 & A & + & + & + & + & + \\
\hline S3 4/9 & 01 & $83 \pm 7$ & II & B & + & + & + & + & + \\
\hline JLL237 & 01 & $4 \pm 2$ & IV & B & + & + & + & + & + \\
\hline 43 & 01 & $22 \pm 5$ & V & $C$ & + & + & + & - & + \\
\hline VIB12 & $\mathrm{O} 2$ & $67 \pm 5$ & II & $E$ & + & + & - & - & + \\
\hline VIB103 & $\mathrm{O} 2$ & $29 \pm 3$ & V & B & + & - & + & + & + \\
\hline VIB160 & $\mathrm{O} 2$ & $6 \pm 2$ & II & $\mathrm{B}$ & + & + & + & + & + \\
\hline JLL143 & $\mathrm{O} 2$ & $23 \pm 4$ & III & D & + & + & + & + & + \\
\hline HI610 & $\mathrm{O} 2$ & $23 \pm 4$ & V & $C$ & + & - & + & + & + \\
\hline VIB113 & $\mathrm{O} 3$ & $3 \pm 3$ & II & D & + & + & + & + & + \\
\hline $\begin{array}{l}\text { CNEVA } \\
\text { NB11008 }\end{array}$ & $\mathrm{O} 3$ & $8 \pm 4$ & II & B & + & + & + & - & + \\
\hline
\end{tabular}




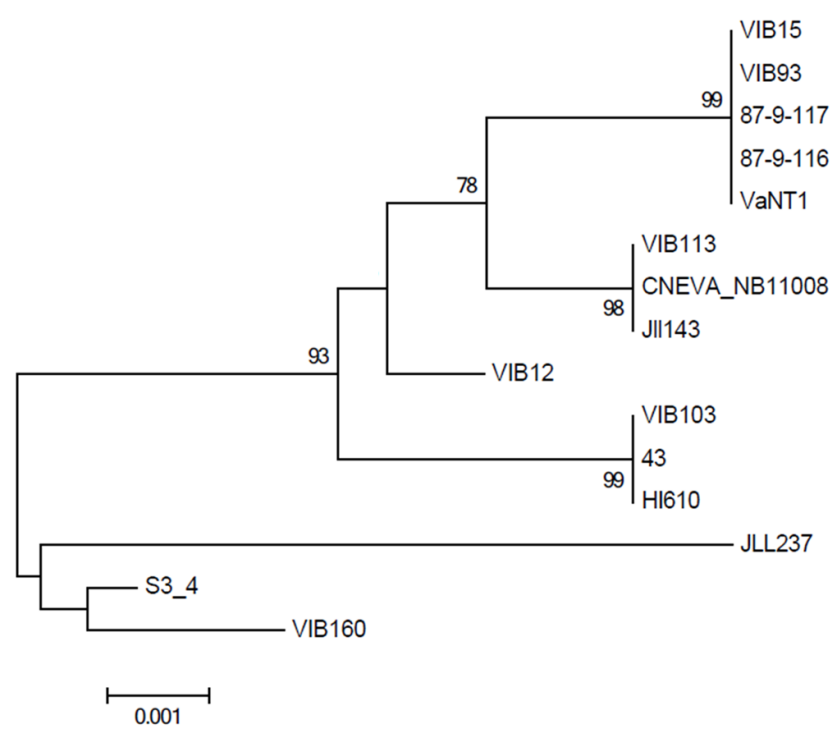

Figure 2. Maximum Likelihood phylogram based on a 2101 bp concatamer of $16 \mathrm{~S}$ rRNA, amiB and $e m p A$ gene sequences of the Vibrio anguillarum isolates investigated in this study. The percentage of trees from 1000 bootstrap resamples supporting the topology is indicated when above 50 .

doi:10.1371/journal.pone.0070477.g002

as well. Cluster V is represented by two O2 strains (HI610 and VIB103), supplemented with one O1 strain (43). Isolates JLL237 (O1 serotype) and JLL143 (O2 serotype) landed in a separate cluster, cluster III and IV, respectively (Fig. 3). Although there is some correspondence between genetic clustering and serotype, our results do not suggest a correlation with the results obtained in our virulence assay, as both the avirulent and virulent strains appear scattered throughout the dendrogram.

\section{Phenotypic Characterization}

For all $V$. anguillarum strains, high metabolic activity was observed, except for the O2 strain VIB12, which only consumed
12 carbon sources (L-arabinose, 2'-deoxyadenosine, adenosine, Dglucose-1-phosphate, D-glucose-6-phosphate, D-fructose-6-phospate, L-lyxose, pyruvic acid, inosine, fumaric acid, L-asparagine, and D-ribose). These findings were confirmed in an independent experiment. Out of 95 carbon sources tested in this study, 40 were consumed by all other $14 \mathrm{~V}$. anguillarum strains (L-arabinose, Dxylose, acetic acid, L-aspartic acid, L-lactic acid, L-alanine, 2'deoxyadenosine, adenosine, D-glucose-6-phosphate, D,L-malic acid, D-fructose-6-phospate, succinic acid, citric acid, L-lyxose, uridine, pyruvic acid, D-sorbitol, inosine, D-gluconic acid, L-malic acid, L-serine, fumaric acid, $\beta$-methyl-D-glucoside, L-asparagine, glycerol, Ala-Gly, L-threonine, Gly-Pro, L-glutamic acid, Dalanine, D-fructose, D-mannose, $\alpha$-D-glucose, sucrose, D-mannitol, L-glutamine, L-proline, D-galactose, D-ribose, and N-acetylD-glucosamine), while 20 were only metabolized by some strains and 35 by none of the strains tested (D-glucuronic acid, Dglucosaminic acid, 1,2-propanediol, $\alpha$-methyl-D-galactoside, Lrhamnose, D-threonine, mucic acid, D-aspartic acid, L-fucose, ahydroxyglutaric acid-g-lactone, D-galactonic acid- $\gamma$-lactone, Dsaccharic acid, m-tartaric acid, adonitol, glyoxylic acid, glycolic acid, $\alpha$-D-lactose, $\mathrm{N}$-acetyl-D-mannosamine, acetoacetic acid, lactulose, tricarballylic acid, tyramine, glucoronamide, D-melibiose, m-hydroxyphenyl acetic acid, D-malic acid, L-galactonic acid$\gamma$-lactone, mono-methylsuccinate, $\mathrm{p}$-hydroxyphenyl acetic acid, Dpsicose, dulcitol, thymidine, 2-aminoethanol, D-galacturonic acid, and phenylethylamine) (Table $\mathrm{S} 1$ ).

Next, the $V$. anguillarum strains were clustered based on the ability to utilize different carbon sources. As can be seen from the UPGMA dendrogram constructed from the PM1 profiles (area under the curve), clear differences can be observed between the studied $V$. anguillarum strains (Fig. 4; Table 2). Based on 90\% similarity, five clusters can be identified, of which cluster A perfectly matched cluster I obtained by genotyping. The two O3 strains, CNEVA NB1 1008 and VIB113, which clustered together by genotyping (cluster II), were separated in this analysis (cluster B and D, respectively). Strains HI610 (O2 serotype) and 43 (O1 serotype) clustered together in cluster $\mathrm{C}$, which is in agreement with the genotyping results (clusters V). Cluster B contained two O1 strains, JLL237 and S3 4/9, two O2 strains, VIB103 and
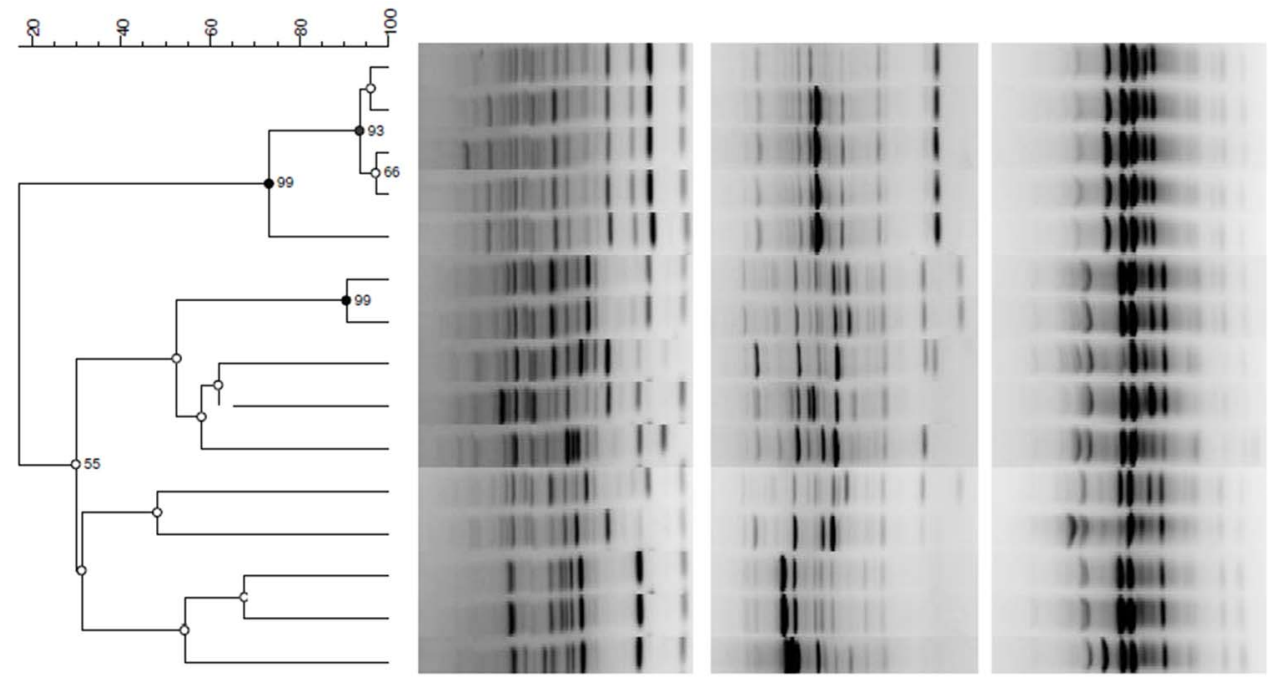

\begin{tabular}{|c|c|}
\hline Strain & Serotype \\
\hline $87-9-116$ & $\mathrm{O} 1$ \\
\hline $87-9-117$ & $\mathrm{O} 1$ \\
\hline VaNT1 & 01 \\
\hline VIB93 & $\mathrm{O} 1$ \\
\hline VIB15 & 01 \\
\hline CNEVA NB11008 & $\mathrm{O} 3$ \\
\hline VIB113 & $\mathrm{O} 3$ \\
\hline S3 4/9 & 01 \\
\hline VIB12 & $\mathrm{O} 2$ \\
\hline VIB160 & $\mathrm{O} 2$ \\
\hline ЛL143 & $\mathrm{O} 2$ \\
\hline$\pi L 237$ & 01 \\
\hline 43 & 01 \\
\hline HI- 610 & $\mathrm{O} 2$ \\
\hline VIB103 & $\mathrm{O} 2$ \\
\hline
\end{tabular}

Figure 3. RAPD (two gels on the left) and rep-PCR (gel on the right) fingerprints and corresponding dendrogram (combined datasets) derived from UPGMA linkage of Pearson correlation coefficients of the Vibrio anguillarum isolates investigated in this study. The percentage of trees from 100 bootstrap resamples supporting the topology is indicated when above 50 . doi:10.1371/journal.pone.0070477.g003 
VIB160, and one O3 strain, CNEVA NB11008. Cluster C contained strains JLL143 (O2 serotype) and VIB113 (O3 serotype). As previously mentioned, the O2 strain VIB12 showed very low metabolic activity and therefore clustered separately. Similar to the genotypic analysis, no correlation could be observed between virulence and the phenotypic analysis.

In addition, the production of extracellular enzymes, which are possibly involved in virulence and invasion of host tissue [44], of the $15 \mathrm{~V}$. anguillarum strains was determined on agar plates containing various substrates (Table 2). Strain VIB12 lacked both caseinase and hemolytic activity, which may explain its avirulent behavior. Remarkably, although strain VIB15 was identified as a virulent strain towards sea bass larvae, it was the only strain which did not contain lipase activity. Likewise, two virulent $\mathrm{O} 2$ strains, VIB103 and HI610, were deficient in phospholipase activity. Finally, no hemolytic activity was detected in the avirulent strain 87-9-116, and the virulent strains 43 and CNEVA NB11008, belonging to serotype $\mathrm{O} 1, \mathrm{O} 2$ and $\mathrm{O} 3$, respectively (data not shown).

\section{Discussion}

In this study, a set of $15 \mathrm{~V}$. anguillarum strains from different origins (sea bass, trout and cod, or sediment) were subjected to a previously designed standardized virulence assay using axenic European sea bass larvae as hosts [25]. Here, the utility of the method to assess and compare the virulence of different $V$. anguillarum strains was demonstrated on a larger scale for the first time. Out of the 15 tested strains ten isolates were categorized as virulent strains, whereas five isolates were found to be avirulent. In general, our results were in line with other virulence characterization studies of $V$. anguillarum. For example, strains VIB15, VIB103, 87-9-117, JLL143, JLL237 and CNEVA NB11008, which were found to be virulent in other studies $([28,32,33], \mathrm{M}$. Halberg Larsen, unpublished data), were also virulent in our study. Additionally, strains VIB93, 87-9-116, VaNT1 and S3 4/9 which were avirulent in earlier studies $([8,28,30,45]$, M. Halberg Larsen, unpublished data), were avirulent here as well. On the other hand, the virulence characteristics of strains VIB160 and VIB113, which were both virulent in our study, were in contrast to previous studies [28]. This discrepancy may be explained by a different host specificity combined with the use of a different infection model system, i.e. intraperitoneal injection of Atlantic salmon versus challenge of sea bass larvae by immersion [46,47]. Additionally, despite strain VIB12 was originally isolated from a diseased sea bass, this strain was found to be avirulent in our screening system. Potentially, this could be explained by the developmental stage of the fish or potential co-infections facilitating entry of $V$. anguillarum in the adult fish.

Although the virulence plasmid $\mathrm{pJM} 1$ is generally regarded as an important virulence factor in $V$. anguillarum, no strict relation between the presence of the plasmid and virulence was detected in our study. For example, serotype O1 strains VaNT1 and VIB93, both containing the virulence plasmid $[8,28]$, were found to be avirulent in our study. It is well known that bacteria can be deprived of their plasmids during storage or passage of the strains [48]. Therefore, presence or absence of $\mathrm{pJM} 1$ was verified for all our strains based on plasmid isolation and sequencing, confirming the strain characteristics. The avirulent character of these strains on sea bass larvae, both originally isolated from rainbow trout,

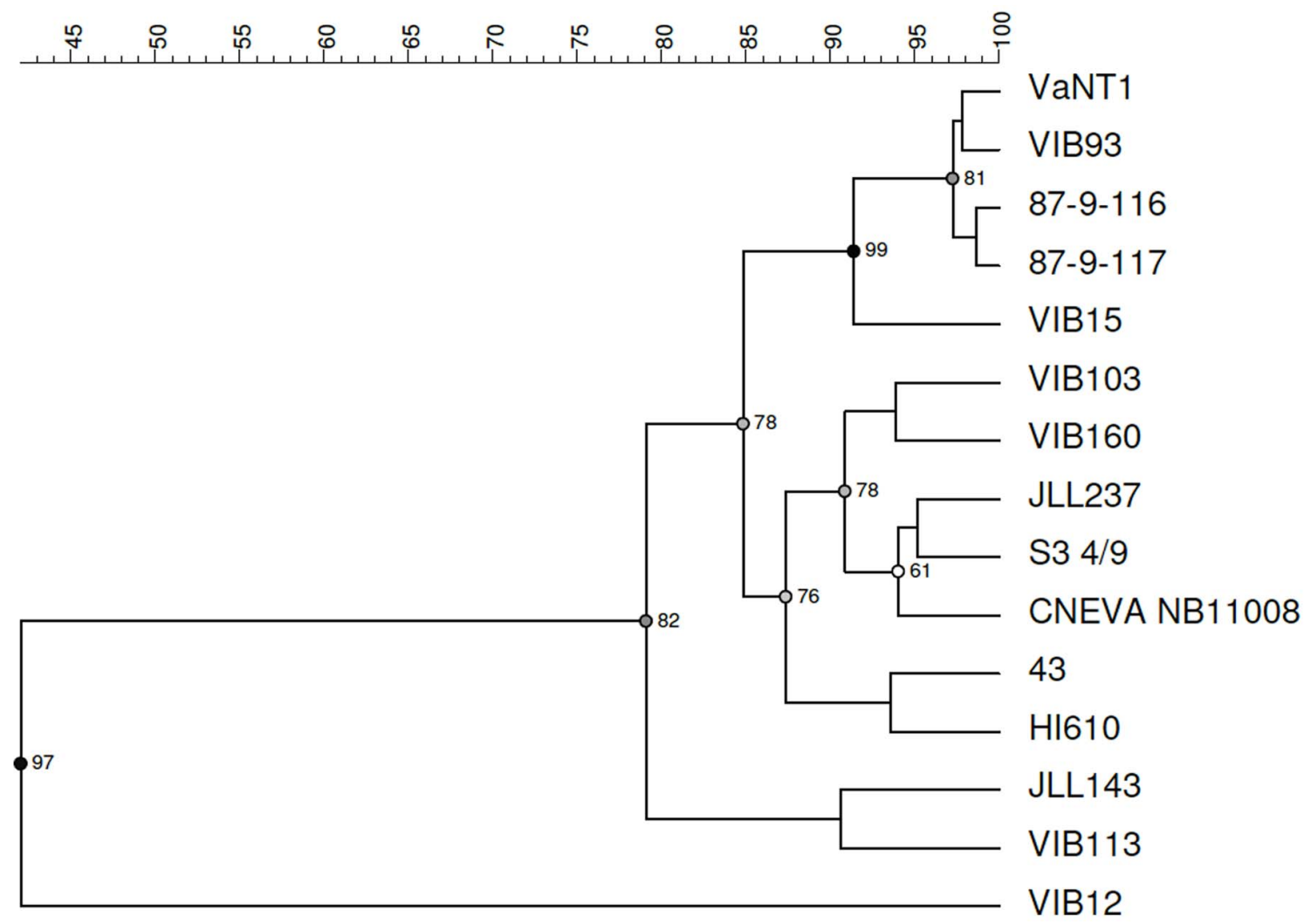

Figure 4. Biolog PM1 phenotypes within Vibrio anguillarum strains. The dendrogram was derived by UPGMA cluster analysis of the Biolog PM1 data (i.e. area under the curve) of the 15 selected V. anguillarum strains. The results were validated using cophenetic correlation. doi:10.1371/journal.pone.0070477.g004 
may be explained by a stringent host specificity, which may differ from strain to strain (see earlier). In addition, the lack of virulence of VaNT1 may be explained by its "rough" colony morphology [8]. It has been recognized that rough strains, which lack the lipopolysaccharide O-antigen, are more susceptible to complement-mediated killing, resulting in an avirulent phenotype [17,49]. In contrast, two other Ol serotype strains that contain the virulence plasmid (VIB15 and 87-9-117) did result in a high mortality of the sea bass larvae, and, remarkably, strains lacking the virulence plasmid were found to cause high mortality in our study system (43 and JLL237). However, as plasmidless O1 strains may have a chromosome-encoded iron sequestering system instead of the pJM1 plasmid-encoded iron uptake system, its function may have remained intact, contributing to its virulence $[50,51]$. These data strongly suggest that presence of the virulence plasmid is not crucial for full virulence towards sea bass larvae.

In order to assess potential relationships between virulence and genotypic and phenotypic characteristics, the strains were subjected to both genotypic and phenotypic characterization. Next to sequence analysis of a number of housekeeping genes, strains were genotyped using RAPD and rep-PCR, both used successfully for epidemiological studies of fish pathogens previously [52-55]. The clustering based on the genetic fingerprints showed high similarity with the phylogenetic clustering, but had a much higher discriminatory power. However, whereas some correspondence between genotype and serotype could be observed, no relation could be found with virulence. In addition, similar to Vandenberghe et al. [56], a high phenotypic heterogeneity within the $V$. anguillarum isolates was observed. Nevertheless, again no correlation could be made with virulence. On the contrary, despite some exceptions, in general there was a good agreement between the phenotypic and genotypic clustering. One exception involves the two O3 strains VIB113 and CNEVA NB11008 which grouped in different clusters based on the phenotypic characterization, because of a few differences in carbon utilization. Strain VIB 113 was for example unable to metabolize maltose and maltotriose in contrast to strain CNEVA NB11008. Furthermore, the distinct ecological niches from which these two strains were isolated, i.e. sea bass in France (CNEVA NB11008) versus rainbow trout in Denmark (VIB113), might explain the differences in carbon source utilization patterns. Keymer et al. [57] also observed a phenotypic diversity between coastal Vibrio cholerae strains isolated from different environments. An explanation for the low metabolic activity of VIB12 could not be found. This strain did not show any differences in growth characteristics in TSB $+1 \% \mathrm{NaCl}$ compared to the other $V$. anguillarum strains using the indirect Rapid Automated Bacterial Impedance Technique (RABIT) from Don Whitley Scientific (Shipley, UK) (data not shown), demonstrating similar growth kinetics among the different isolates.

\section{References}

1. FAO (2012) The State of World Fisheries and Aquaculture 2012. Food and Agriculture Organization of the United Nations, Rome.

2. Frans I, Lievens B, Heusdens C, Willems K (2008) Detection and identification of fish pathogens: what is the future? The Israeli Journal of Aquaculture 60: $211-$ 227.

3. Aguirre-Guzman G, Ruiz HM, Ascencio F (2004) A review of extracellular virulence product of Vibrio species important in diseases of cultivated shrimp. Aquaculture Research 35: 1395-1404.

4. Paillard G, Leroux F, Borrego JJ (2004) Bacterial disease in marine bivalves: review of recent studies: trends and evolution. Aquatic Living Resources 17: 477-498.

5. Toranzo AE, Magarinos B, Romalde JL (2005) A review of the main bacterial fish diseases in mariculture systems. Aquaculture 246: 37-61.

6. Actis LA, Tolmasky ME, Crosa JH (1999) Vibriosis. In: Woo PTK, Bruno DW (eds) Fish diseases and disorders, Vol 3. Viral, bacterial and fungal infections. CABI Publishing, New York, 523-558.
In addition to the Omnilog Phenotyping, the production of extracellular enzymes potentially involved in virulence was determined for each isolate. Indeed, it was demonstrated that the avirulent strain VIB12 lacked both caseinase and hemolytic activity. However, no clear relation between enzymatic activity and virulence could be observed in this study. For example, although phospholipase activity has been previously described to be an important virulence factor for $V$. vulnificus, two virulent $V$. anguillarum strains, VIB103 and HI610, lacked phospholipase activity [58]. In addition, although strain VIB15 was identified as a virulent strain towards sea bass larvae, it was the only strain lacking lipase activity. Finally, no hemolytic activity was detected in avirulent strain 87-9-116, and in virulent strains 43, CNEVA $\mathrm{NB} 11008$, belonging to serotype $\mathrm{O} 1, \mathrm{O} 2$ and $\mathrm{O} 3$, respectively.

Altogether, the genetic and phenotypic properties of the $15 \mathrm{~V}$. anguillarum isolates assessed in this study could not be correlated to the virulence towards sea bass larvae. This illustrates the complexity of the virulence mechanisms in $V$. anguillarum and suggests that virulence in $V$. anguillarum is highly multifactorial and cannot be assigned to one or a few crucial virulence factors. It is clear that further research is necessary to elucidate the underlying mechanisms of virulence differences in $V$. anguillarum. Using standardized virulence assays such as the one used in this study, together with whole genome sequencing [59], sequencing of whole transcriptomes [60] or epigenetics research [61], we should be able to increase our understanding of $V$. anguillarum virulence. However, anticipating on the different advantages of using a gnotobiotic screening method, it is acknowledged that real-life conditions will always be far more complex and that findings made under gnotobiotic conditions will need to be validated.

\section{Supporting Information}

Table S1 Results of the OmniLog ${ }^{\circledR}$ PM Kinetic analysis of 15 selected Vibrio anguillarum strains grown on a PM1 Phenotype MicroArrayTM plate. For each strain and each carbon source, the area under the curve is presented. Values below 5000 and above 8000 are indicated in red and green respectively.

(XLS)

\section{Acknowledgments}

The authors would like to thank Brigitte Van Moffaert for her excellent technical support.

\section{Author Contributions}

Conceived and designed the experiments: IF KW BL PB CM HR. Performed the experiments: IF. Analyzed the data: IF SG AVA. Contributed reagents/materials/analysis tools: JL ML CM PB KD HR. Wrote the paper: IF BL HR.

7. Austin B, Austin DA (2007) Bacterial fish pathogens: diseases of farmed and wild fish, 4th edn. Praxis Publishing, Chichester.

8. Pedersen K, Grisez L, van Houdt R, Tiainen T, Ollevier F, et al. (1999) Extended serotyping scheme for Vibrio anguillarum with the definition and characterization of seven provisional O-serogroups. Current Microbiology 38: 183-189.

9. Frans I, Michiels CW, Bossier P, Willems KA, Lievens B, et al. (2011) Vibrio anguillarum as a fish pathogen: virulence factors, diagnosis and prevention. Journal of Fish Diseases 34: 643-661.

10. Naka H, Crosa JH (2011) Genetic determinants of virulence in the marine fish pathogen Vibrio anguillarum. Fish Pathology 46: 1-10.

11. Denkin SM, Nelson DR (2004) Regulation of Vibrio anguillarum empA metalloprotease expression and its role in virulence. Applied and Environmental Microbiology 70: 4193-4204. 
12. Mo Z, Guo D, Mao Y, Ye X, Zou Y, et al.(2010) Identification and characterization of the Vibrio anguillarum prt $V$ gene encoding a new metalloprotease. Chinese Journal of Oceanology and Limnology 28: 55-61.

13. Hirono I, Masuda T, Aoki T (1996) Cloning and detection of the haemolysin gene of Vibrio anguillarum. Microbial Pathogenesis 21: 173-182.

14. Rodkhum C, Hirono I, Crosa JH, Aoki T (2005) Four novel haemolysin genes of Vibrio anguillarum and their virulence to rainbow trout. Microbial Pathogenesis 39: 109-119.

15. Rock JL, Nelson DR (2006) Identification and characterization of a hemolysin gene cluster in Vibrio anguillarum. Infection and Immunity 74: 2777-2786.

16. Li L, Rock JL, Nelson DR (2008) Identification and characterization of a repeatin-toxin gene cluster in Vibrio anguillarum. Infection and Immunity 76: 26202632.

17. Boesen HT, Pedersen K, Larsen JL, Koch C, Ellis AE (1999) Vibrio anguillarum resistance to rainbow trout (Oncorhynchus mykiss) serum: role of O-antigen structure of lipopolysaccharide. Infection and Immunity 67: 294-301.

18. Welch TJ, Crosa JH (2005) Novel role of the lipopolysaccharide O1 side chain in ferric siderophore transport and virulence of Vibrio anguillarum. Infection and Immunity 73: 5864-5872.

19. Lindell K, Fahlgren A, Hjerde E, Willassen N, Fällman M, et al. (2012) Lipopolysaccharide $\mathrm{O}$-antigen prevents phagocytosis of Vibrio anguillarum by rainbow trout (Oncorhynchus mykiss) skin epithelial cells. PLoS ONE 7: 1-13.

20. Stork M, Lorenzo MD, Welch TJ, Crosa LM, Crosa JH (2002) Plasmidmediated iron uptake and virulence in Vibrio anguillarum. Plasmid 48: 222-228.

21. Conchas RF, Lemos ML, Barja JL, Toranzo AE (1991) Distribution of plasmidand chromosome-mediated iron uptake systems in Vibrio anguillarum strains of different origins. Applied and Environmental Microbiology 57: 2956-2962.

22. Balado M, Osorio CR, Lemos ML (2006) A gene cluster involved in the biosynthesis of vanchrobactin, a chromosome-encoded siderophore produced by Vibrio anguillarum. Microbiology 152: 3517-3528.

23. Balado M, Osorio CR, Lemos ML (2008) Biosynthetic and regulatory elements involved in the production of the siderophore vanchrobactin in Vibrio anguillarum. Microbiology 154: 1400-1413.

24. Soengas RG, Anta G, Espada A, Paz V, Ares IR, et al. (2006) Structural characterization of vanchrobactin, a new catechol siderophore produced by the fish pathogen Vibrio anguillarum serotype O2. Tetrahedron Letters 47: 7113 7116 .

25. Dierckens K, Rekecki A, Laureau S, Sorgeloos P, Boon N, et al. (2009) Development of a Listonella (Vibrio) anguillarum challenge test for gnotobiotic sea bass (Dicentrarchus labrax) larvae. Environmental Microbiology 11: 526-533.

26. FAO 2005-2012. Cultured Aquatic Species Information Programme. Dicentrarchus labrax. Cultured Aquatic Species Information Programme. Text by Bagni, M. In: FAO Fisheries and Aquaculture Department, Rome.

27. Bochner BR, Gadzinski P, Panomitros E (2001) Phenotype microarrays for highthroughput phenotypic testing and assay of gene function. Genome Research 11: 1246-1255.

28. Austin B, Alsina M, Austin DA, Blanch AR, Grimont F, et al. (1995) Identification and typing of Vibrio anguillarum: a comparison of different methods. Systematic and Applied Microbiology 18: 285-302.

29. Pedersen K, Larsen JL (1995) Evidence for the existence of distinct populations of Vibrio anguillarum serogroup $\mathrm{O} 1$ based on plasmid contents and ribotypes. Applied and Environmental Microbiology 61: 2292-2296.

30. Skov MN, Pedersen K, Larsen JL (1995) Comparison of pulsed-field gel electrophoresis, ribotyping, and plasmid profiling for typing of Vibrio anguillarum serovar O1. Applied and Environmental Microbiology 61: 1540-1545.

31. Grisez L, Chair M, Sorgeloos P, Ollevier F (1996) Mode of infection and spread of Vibrio anguillarum in turbot Scophthalmus maximus larvae after oral challenge through live feed. Diseases of Aquatic Organisms 26: 181-187.

32. Tiainen T, Pedersen K, Larsen JL (1997) Vibrio anguillarum serogroup O3 and V. anguillarum-like serogroup $\mathrm{O} 3$ cross-reactive species - comparison and characterization. Journal of Applied Microbiology 82: 211-218.

33. Bay L, Larsen JL, Leisner JJ (2007) Distribution of three genes involved in the PJM1 iron-sequestering system in various Vibrio anguillarum serogroups. Systematic and Applied Microbiology 30: 85-92.

34. Lievens B, Brouwer M, Vanachter ACRC, Levesque CA, Cammue BPA, et al. (2003) Design and development of a DNA array for rapid detection and identification of multiple tomato vascular wilt pathogens. FEMS Microbiology Letters 223: 113-122.

35. Ahn SH, Kim DG, Jeong SH, Hong GE, Kong IS (2006) Isolation of Nacetylmuramoyl-L-alanine amidase gene $($ amiB $)$ from Vibrio anguillarum and the effect of $a m i B$ gene deletion on stress responses. Journal of Microbiology and Biotechnology 16: 1416-1421.

36. Lane DJ (1991) $16 \mathrm{~S}$ and 23S rRNA sequencing. In: Stackebrandt E, Goodfellow M (eds) Nucleic acids techniques in bacterial systematics. John Wiley \& Sons, Chichester, 115-175

37. Marchesi JR, Sato T, Weightman AJ, Martin TA, Fry JC, et al. (1998) Design and evaluation of useful bacterium-specific PCR primers that amplify genes coding for bacterial 16S rRNA. Applied and Environmental Microbiology 64: 795-799.
38. Xiao P, Mo ZL, Mao YX, Wang CL, Zou YX, et al. (2009) Detection of Vibrio anguillarum by PCR amplification of the empA gene. Journal of Fish Diseases 32: 293-296.

39. Hong GE, Kim DG, Bae JY, Ahn SH, Bai SC, et al. (2007) Species-specific PCR detection of the fish pathogen, Vibrio anguillarum, using the amiB gene, which encodes N-acetylmuramoyl-L-alanine amidase. FEMS Microbiology Letters 269: 201-206.

40. Tamura K, Peterson D, Peterson N, Stecher G, Nei M, et al. (2011) MEGA5: Molecular evolutionary genetics analysis using maximum likelihood, evolutionary distance, and maximum parsimony methods. Molecular Biology and Evolution 28: 2731-2739.

41. Versalovic J, Schneider M, De Bruijn FJ, Lupski JR (1994) Genomic fingerprinting of bacteria using repetitive sequence-based polymerase chain reaction. Methods in Molecular and Cellular Biology 5: 25-40.

42. Vauterin L, Vauterin P (1992) Computer-aided objective comparison of electrophoresis patterns for grouping and identification of microorganisms. Eur Microbiol 1: 37-41.

43. Russek-Cohen E, Colwell RR (1996) Numerical classification of microorganisms. In: Akkermans ADL, Van Elsas JD, De Bruijn FJ (eds) Molecular Microbial Ecology Manual. Kluwer Academic Publishers, Dordrecht, The Netherlands, 1-21.3.2.1.

44. Natrah FMI, Ruwandeepika HAD, Pawar S, Karunasagar I, Sorgeloos P, et al. (2011) Regulation of virulence factors by quorum sensing in Vibrio harveyi. Veterinary Microbiology 154: 124-129.

45. Pedersen K, Gram L, Austin DA, Austin B (1997) Pathogenicity of Vibrio anguillarum serogroup $\mathrm{O} 1$ compared to plasmids, outer membrane proteins profiles and siderophore production. Journal of Applied Microbiology 82: 365371.

46. Larsen JL, Pedersen K, Dalsgaard I (1994) Vibrio anguillarum serovars associated with vibriosis in fish. Journal of Fish Diseases 17: 259-267.

47. Mikkelsen H, Lund V, Martinsen LC, Gravningen K, Schroder MB (2007) Variability among Vibrio anguillarum $\mathrm{O} 2$ isolates from Atlantic cod (Gadus morhua L.): characterisation and vaccination studies. Aquaculture 266: 16-25.

48. Sørensen SJ, Bailey M, Hansen LH, Kroer N, Wuertz S (2005) Studying plasmid horizontal gene transfer in situ: a critical review. Nature Reviews Microbiology 3 : 700-710.

49. Swain P, Behera T, Mohapatra D, Nanda PK, Nayak SK, et al. (2010) Derivation of rough attenuated variants from smooth virulent Aeromonas hydrophila and their immunogenicity in fish. Vaccine 28: 4626-4631.

50. Naka H, López CS, Crosa JH (2008) Reactivation of the vanchrobactin siderophore system of Vibrio anguillarum by removal of a chromosomal insertion sequence originated in plasmid $\mathrm{pJM} 1$ encoding the anguibactin siderophore system. Environmental Microbiology 10: 265-277.

51. Balado M, Osorio CR, Lemos ML (2009) FvtA is the receptor for the siderophore vanchrobactin in Vibrio anguillarum: utility as a route of entry for vanchrobactin analogues. Applied and Environmental Microbiology 75: 27752783.

52. Romalde JL, Magariños B, Villar C, Barja JL, Toranzo AE (1999) Genetic analysis of turbot pathogenic Streptococcus parauberis strains by ribotyping and ramdom amplified polymorphic DNA. FEMS Microbiology Letters 179: 297304.

53. Wong H, Lin C (2001) Evaluation of typing of Vibrio parahaemolyticus by three PCR methods using specific primers. Journal of Clinical Microbiology 39: 42334240

54. Ravelo G, Magarinos SB, Lopez-Romalde S, Toranzo AE, Romalde JL (2003) Molecular fingerprinting of fish-pathogenic Lactococcus garvieae strains by random amplified polymorphic DNA analysis. Journal of Clinical Microbiology 41: 751756.

55. Flemming L, Rawlings D, Chenia H (2007) Phenotypic and molecular characterisation of fish-borne Flavobacterium johnsoniae-like isolates from aquaculture systems in South Africa. Research in Microbiology 158: 18-30.

56. Vandenberghe J, Thompson FL, Gomez-Gil B, Swings J (2003) Phenotypic diversity among Vibrio isolates from marine aquaculture systems. Aquaculture 219: 9-20.

57. Keymer DP, Miller MC, Schoolnik GK, Boehm AB (2007) Genomic and phenotypic diversity of coastal Vibrio cholerae strains is linked to environmental factors. Applied and Environmental Microbiology 73: 3705-3714.

58. Koo B, Lee J, Kim S, Yoon H, Kim K, et al. (2007) Phospholipase A as a potent virulence factor of Vibrio vulnificus. International Journal of Molecular Medicine 20: $913-918$.

59. Rodkhum C, Hirono I, Stork M, Lorenzo MD, Crosa JH, et al. (2006) Putative virulence-related genes in Vibrio anguillarum identified by random genome sequencing. Journal of Fish Diseases 29: 157-166.

60. Sorek R, Cossart P (2010) Prokaryotic transcriptomics: a new view on regulation, physiology and pathogenicity. Nature Reviews Genetics 11: 9-16.

61. Gómez-Díaz E, Jordà M, Peinado MA, Rivero A (2012) Epigenetics of HostPathogen Interactions: The Road Ahead and the Road Behind. PLOS Pathogens 8:e1003007 doi:10.1371/journal.ppat.1003007. 